\title{
Varietal Discrimination of Pineapple (Ananas comosus L.) Using Chromatographic Fingerprints and Chemometrics
}

\author{
Almie Amira Munaras Khan ${ }^{1,}$, Norashikin Saim ${ }^{1}$, Rossuriati Dol Hamid, \\ Rozita Osman ${ }^{1}$, and Siti Raihan Zakaria ${ }^{2}$ \\ ${ }^{1}$ Faculty of Applied Sciences, Universiti Teknologi MARA (UiTM), Shah Alam 40450, Selangor, Malaysia \\ ${ }^{2}$ Faculty of Applied Sciences, Universiti Teknologi MARA Pahang, Jengka 26400, Pahang, Malaysia
}

\author{
*Corresponding author: \\ tel: $+60-173398547$ \\ email:almie.amiramk@yahoo.com
}

Received: July 1, 2019

Accepted: December 8, 2019

DOI: $10.22146 /$ ijc.47159

\begin{abstract}
Online solid-phase extraction-liquid chromatography (online SPE-LC) with diode array detector (DAD) was used to obtain the chromatographic fingerprint of bioactive compounds of pineapple (Ananas comosus L.). The extracts from 40 samples of three different varieties of pineapple (Morris, MD2, and Josaphine) were obtained using pressurized liquid extraction (PLE) prior to separation using online SPE-LC. The SPE-LC method was optimized and validated and applied to 40 pineapple samples of those three varieties. Seven bioactive compounds identified include catechin, epicatechin, chlorogenic acid, ferulic acid, quercetin, myricetin, and bromelain. For varietal discrimination, the relative areas of 16 selected peaks were subjected to chemometric techniques. The three pineapple varieties were successfully discriminated using cluster analysis (CA) and principal component analysis (PCA).
\end{abstract}

Keywords: online SPE-LC; pineapple; bioactive compounds; chromatographic fingerprint; chemometrics

\section{- INTRODUCTION}

Pineapple (Ananas comosus L.) is widely cultivated in tropical countries, including Malaysia [1-2]. Pineapple is known to contain a significant amount of bioactive compounds such as anthocyanins, polyphenols, and bromelain, a health-inducing enzyme. Many studies have reported on the biological properties of pineapple such as anti-oxidative [3], anti-browning [4], anti-inflammatory, and anti-platelet activities [5]. Food policies such as stated in General Food Law Regulation No.178/2002 gives the right to the consumers to obtain truthful information about the fruit they purchased, and the data includes the composition, types, grades, and origin of the food [6]. The current quality control of fruits in Malaysia is based solely on the morphological traits and with the manual inspection done by the agricultural officer [7]. This approach depends on the human's perception and judgment, which may be biased and inconsistent.

The World Health Organization (WHO) has recommended chromatographic fingerprint analysis as a quality control strategy for foods with medicinal values [8-9]. The chromatographic fingerprint of phenolic compounds has been successfully used by researchers in the authentication of honey [10], olive oil [11-12], and herbal medicines [13]. The development of a valuable chromatographic fingerprint requires efficient extraction, cleanup, and separation methods. Pressurized liquid extraction (PLE) has been successfully applied for the extraction of thermal-sensitive bioactive compounds, including phenolic compounds from plants and fruits [14-15]. It involves extraction using solvents in a liquid state at elevated temperature and pressure to enhance the extraction process. For plant extracts, removal of interference and analyte concentration, known as the cleanup step, is usually required prior to analysis [2]. Solid-phase extraction (SPE) usually consists of 4 steps: conditioning/equilibration, loading, washing, and elution. This technique has been largely applied and proved to be a good alternative to traditional liquidliquid extraction. Due to the laborious steps in SPE, an 
online SPE-LC is getting more attention. The SPE process in both approaches follows the same steps and is governed by the same principles. However, using online SPE-LC, the eluted analytes are directly transferred into the analytical column for separation and quantitation. Thus, online SPE-LC approach has the advantages of a significant reduction in sample preparation time and less human handling.

In this study, an online SPE-LC was developed to obtain a chromatographic fingerprint of selected bioactive compounds as an alternative to traditional quality control of pineapple. The developed method was used to analyze three common varieties of pineapple in Malaysia (MD2, Morris, and Josaphine). These varieties were selected because seventy percent of the fresh pineapple fruit produced in Malaysia is from Morris variety. Josaphine pineapple is the most common variety cultivated on an annual cycle in Malaysia, while MD2 variety is listed as major export crop under Malaysia National Key Economic Agenda (NKEA). Chemometric methods such as cluster analysis (CA) and principal component analysis (PCA) were applied to the dataset of the chromatographic fingerprints to discriminate the selected pineapple varieties.

\section{- EXPERIMENTAL SECTION}

\section{Materials}

Forty samples of ripened fruits of three pineapple varieties (Moris, MD2, and Josaphine) were purchased from local traders. The fruits were peeled, cut into thin pieces, and dried for $48 \mathrm{~h}$ at $45^{\circ} \mathrm{C}$ in an oven (Memmert UN110). The dried flesh was stored in a dark-covered container prior to extraction. The standards for selected bioactive compounds (epicatechin, catechin, quercetin, chlorogenic acid, ferulic acid, myricetin, and bromelain) were purchased from Merck (Darmstadt, Germany). Acetonitrile (HPLC grade), methanol (HPLC grade), and acetic acid were purchased from Merck Schuchardt (Hohenbrunn, Germany).

\section{Instrumentation}

\section{Pressurized liquid extraction}

PLE was performed using Dionex ASE 350 accelerated solvent extractor (Thermo Scientific Ltd.
Surrey, UK). The extracts from 40 pineapple samples were obtained using the PLE method. Dried flesh of pineapple $(60 \mathrm{~g})$ was accurately weighed, mixed with an equal amount of diatomaceous earth, and transferred to a $100 \mathrm{~mL}$ PLE stainless steel extraction cell with cellulose filter at the bottom end to eliminate particles in the extracts. The sample cell was then closed to medium tightness and placed into the carousel of the ASE 350 system. Extraction was performed using single cycle mode with $100 \%$ of methanol as the solvent. The extracted analyte was purged from the sample cell using pressurized nitrogen. The PLE parameters were: static cycle, 1; flush volume, 100\%; purge time, $120 \mathrm{sec}$; and the optimized PLE parameters were: extraction temperature, $105^{\circ} \mathrm{C}$; extraction time, $20 \mathrm{~min}$. After PLE, each extract was transferred into online SPE-LC vials before analysis [16].

\section{Online SPE-LC}

Analysis of bioactive compounds was done using online SPE-LC (Dionex Ultimate 3000 Liquid Chromatography system) with diode array detector (DAD) using two C18 columns, a $5 \mu \mathrm{m}, 4.6 \mathrm{~mm} \times 50$ $\mathrm{mm}$ for SPE cleanup and a $5 \mu \mathrm{m}, 4.6 \mathrm{~mm} \times 250 \mathrm{~mm}$ for separation of compounds. The column temperature was maintained at $40^{\circ} \mathrm{C}$ in an oven, and the injection volume was $100 \mu \mathrm{L}$. Eluted compounds were monitored at the optimized detection wavelength of $280 \mathrm{~nm}$. Data acquisition was performed by Chromeleon software. The mobile phase consisted of ultrapure water (A), methanol (B), and acetonitrile (C). The separation done with application of gradient elution 0-19 min: 50\% A: 20\% B: 30\% C; $20-25$ min: gradient elution 15\% A: 40\% B: $45 \%$ C; $25-40$ min: gradient elution $10 \%$ A: $80 \%$ B: $10 \% \mathrm{C}$. The flow rate was set at $1 \mathrm{~mL} / \mathrm{min}$ throughout the analysis [17]. Fig. 1 shows the chromatogram of selected bioactive compounds obtained using the optimized online SPE-LC method.

\section{Procedure}

\section{Calibration and linearity}

The standard solution of all bioactive compounds was prepared in HPLC grade methanol. The concentration of standards of bioactive compounds was 


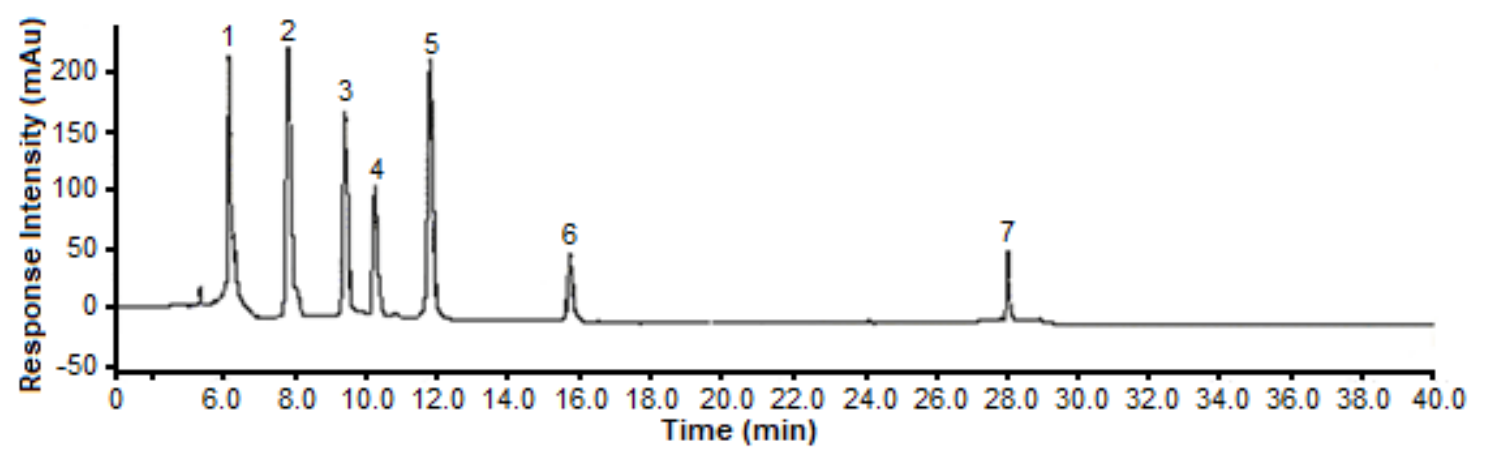

Fig 1. Chromatogram of selected bioactive compounds standards (100 mg/L), 1) catechin; 2) epicatechin; 3) chlorogenic acid; 4) ferulic acid; 5) myricetin; 6) quercetin; 7) bromelain

prepared between $5-200 \mathrm{mg} / \mathrm{L}$ for quantification in pineapple samples. Linearity was determined as $\left(\mathrm{R}^{2}\right)$ of the calibration graph. The coefficient of determination showed good linearity $\left(\mathrm{R}^{2}>0.997\right)$ as shown in Table 1 .

\section{Precision}

The repeatability of this method was conducted using three replicates of the standard mixture $(50 \mathrm{mg} / \mathrm{L})$ to give low percent RSD ranging between 2.1-4.6\% (Table 1).

\section{Limit of detection and limit of quantitation}

The limit of detection (LOD) and quantification (LOQ) were determined based on the signal-to-noise ratio $(\mathrm{S} / \mathrm{N})$ of about 3 and 10 , respectively. The LOD values were between 2.4 and $5.2 \mathrm{mg} / \mathrm{L}$, while the LOQ values were between 8.2 and $17.1 \mathrm{mg} / \mathrm{L}$ for each standard compound (Table 1).

\section{Data analysis}

Chemometric analysis applied on the dataset of chromatographic fingerprints was done using XLSTAT 2013 software (Addinsoft, New York, NY). Peak areas of
16 selected peaks were utilized as variables to evaluate the similarities and differences in CA and PCA.

\section{- RESULTS AND DISCUSSION}

Identification of selected bioactive compounds in pineapple samples was performed by comparing their retention times and UV spectra with that of the standard compounds. Fig. 2 shows the chromatograms of representative samples from the three pineapple varieties and Table 2 tabulates the amount of selected bioactive compounds in all pineapple samples. Bromelain, epicatechin and chlorogenic acid existed in all pineapple varieties. The amount of catechin was found highest in Josaphine pineapple $(5.23 \mathrm{mg}$ in $100 \mathrm{~g}$ of dried pineapple), but not detected in most MD2 samples. The presence of catechin and epicatechin was reported by a study on the Bali pineapple [18]. Catechin was also reported in grapes and teas in high amount [19]. Epicatechin, however, showed a higher amount in MD2 varieties than in other varieties.

Table 1. Coefficients of determination, precision, limit of detection (LOD) and limit of quantification (LOQ) of selected bioactive compounds

\begin{tabular}{lcccc}
\hline Compounds & $\begin{array}{c}\text { Correlation } \\
\text { coefficient }\left(\mathrm{R}^{2}\right)\end{array}$ & $\begin{array}{c}\mathrm{LOD} \\
\left(\mathrm{mg} \mathrm{L}^{-1}\right)\end{array}$ & $\begin{array}{c}\mathrm{LOQ} \\
\left(\mathrm{mg} \mathrm{L}^{-1}\right)\end{array}$ & $\begin{array}{c}\text { Precision } \\
(\% \mathrm{RSD})\end{array}$ \\
\hline Catechin & 0.997 & 4.2 & 14.1 & 3.2 \\
Epicatechin & 0.975 & 4.5 & 15.3 & 2.1 \\
Chlorogenic acid & 0.994 & 5.2 & 17.1 & 3.9 \\
Ferulic acid & 0.997 & 3.4 & 11.2 & 2.8 \\
Quercetin & 0.994 & 2.4 & 8.2 & 4.6 \\
Myricetin & 0.995 & 3.6 & 12.0 & 4.3 \\
Bromelain & 0.995 & 3.1 & 9.6 & 2.6 \\
\hline
\end{tabular}


Table 2. Quantitative determination of bioactive compounds in pineapple samples $(\mathrm{mg} / 100 \mathrm{~g}$ dried pineapples \pm RSD $(\mathrm{n}=3)$, ND: not detected

\begin{tabular}{|c|c|c|c|c|c|c|c|}
\hline Samples & Catechin & Epicatechin & Chlorogenic acid & Ferulic acid & Myricetin & Quercetin & Bromelain \\
\hline J1 & $4.483 \pm 0.002$ & $1.799 \pm 0.002$ & $1.343 \pm 0.032$ & $1.077 \pm 0.001$ & $0.222 \pm 0.021$ & $0.635 \pm 0.011$ & $7.345 \pm 0.003$ \\
\hline $\mathrm{J} 2$ & $4.827 \pm 0.012$ & $1.873 \pm 0.003$ & $1.392 \pm 0.001$ & $0.833 \pm 0.064$ & $0.155 \pm 0.011$ & $0.744 \pm 0.002$ & $7.637 \pm 0.005$ \\
\hline $\mathrm{J} 3$ & $4.601 \pm 0.041$ & $1.947 \pm 0.011$ & $1.445 \pm 0.002$ & $1.109 \pm 0.011$ & $0.302 \pm 0.001$ & $0.619 \pm 0.004$ & $7.762 \pm 0.029$ \\
\hline $\mathrm{J} 4$ & $3.552 \pm 0.029$ & $2.058 \pm 0.052$ & $1.705 \pm 0.001$ & $1.267 \pm 0.003$ & $0.237 \pm 0.005$ & $0.249 \pm 0.001$ & $6.476 \pm 0.063$ \\
\hline J5 & $4.459 \pm 0.011$ & $2.080 \pm 0.033$ & $1.004 \pm 0.031$ & $0.956 \pm 0.022$ & $0.329 \pm 0.006$ & $0.674 \pm 0.083$ & $7.707 \pm 0.041$ \\
\hline J6 & $4.769 \pm 0.005$ & $1.915 \pm 0.041$ & $1.415 \pm 0.011$ & $0.835 \pm 0.015$ & $0.217 \pm 0.006$ & $0.421 \pm 0.002$ & $8.001 \pm 0.011$ \\
\hline J7 & $4.824 \pm 0.003$ & $2.048 \pm 0.001$ & $1.101 \pm 0.015$ & $1.315 \pm 0.021$ & $0.279 \pm 0.003$ & $0.436 \pm 0.016$ & $8.058 \pm 0.002$ \\
\hline J8 & $3.388 \pm 0.010$ & $1.908 \pm 0.006$ & $1.335 \pm 0.048$ & $1.151 \pm 0.002$ & $0.325 \pm 0.017$ & $0.593 \pm 0.003$ & $11.443 \pm 0.001$ \\
\hline J9 & $5.166 \pm 0.001$ & $2.085 \pm 0.008$ & $1.419 \pm 0.001$ & $1.242 \pm 0.001$ & $0.270 \pm 0.002$ & $0.625 \pm 0.002$ & $7.002 \pm 0.004$ \\
\hline $\mathrm{J} 10$ & $4.450 \pm 0.005$ & $1.985 \pm 0.022$ & $1.742 \pm 0.017$ & $1.283 \pm 0.003$ & $0.248 \pm 0.039$ & $0.754 \pm 0.001$ & $8.155 \pm 0.042$ \\
\hline J11 & $4.858 \pm 0.012$ & $1.843 \pm 0.061$ & $1.219 \pm 0.002$ & $1.023 \pm 0.046$ & $0.137 \pm 0.003$ & $0.358 \pm 0.023$ & $9.284 \pm 0.002$ \\
\hline J12 & $3.794 \pm 0.009$ & $1.853 \pm 0.002$ & $1.459 \pm 0.048$ & $1.362 \pm 0.003$ & $0.307 \pm 0.054$ & $0.470 \pm 0.004$ & $7.948 \pm 0.014$ \\
\hline J13 & $4.883 \pm 0.018$ & $2.077 \pm 0.002$ & $1.536 \pm 0.033$ & $1.402 \pm 0.021$ & $0.218 \pm 0.012$ & $0.828 \pm 0.024$ & $11.590 \pm 0.013$ \\
\hline J14 & $5.233 \pm 0.009$ & $2.238 \pm 0.008$ & $1.302 \pm 0.012$ & $1.455 \pm 0.001$ & $0.146 \pm 0.003$ & $0.884 \pm 0.001$ & $7.838 \pm 0.007$ \\
\hline J15 & $3.992 \pm 0.071$ & $1.867 \pm 0.032$ & $1.429 \pm 0.038$ & $1.008 \pm 0.003$ & $0.196 \pm 0.029$ & $0.663 \pm 0.003$ & $10.323 \pm 0.005$ \\
\hline M1 & $2.399 \pm 0.002$ & $0.235 \pm 0.001$ & $0.651 \pm 0.071$ & ND & ND & $0.080 \pm 0.031$ & $2.898 \pm 0.048$ \\
\hline M2 & $2.176 \pm 0.016$ & $0.104 \pm 0.006$ & $0.751 \pm 0.001$ & ND & ND & ND & $3.425 \pm 0.025$ \\
\hline M3 & $2.571 \pm 0.003$ & $0.261 \pm 0.003$ & $0.716 \pm 0.006$ & ND & ND & ND & $3.251 \pm 0.032$ \\
\hline M4 & $2.789 \pm 0.006$ & $0.278 \pm 0.019$ & $0.761 \pm 0.008$ & ND & ND & ND & $2.908 \pm 0.011$ \\
\hline M5 & $2.781 \pm 0.002$ & $0.604 \pm 0.008$ & $0.639 \pm 0.025$ & ND & ND & ND & $3.583 \pm 0.002$ \\
\hline M6 & $2.544 \pm 0.038$ & $0.450 \pm 0.013$ & $0.578 \pm 0.043$ & ND & ND & ND & $4.077 \pm 0.006$ \\
\hline M7 & $2.925 \pm 0.004$ & $0.202 \pm 0.064$ & $0.549 \pm 0.002$ & ND & ND & ND & $2.878 \pm 0.002$ \\
\hline M8 & $2.363 \pm 0.006$ & $0.154 \pm 0.002$ & $0.668 \pm 0.005$ & ND & ND & ND & $6.371 \pm 0.015$ \\
\hline M9 & $2.781 \pm 0.036$ & $0.124 \pm 0.042$ & $0.483 \pm 0.011$ & ND & ND & ND & $3.376 \pm 0.004$ \\
\hline M10 & $2.544 \pm 0.062$ & $0.086 \pm 0.011$ & $0.620 \pm 0.035$ & ND & ND & ND & $4.032 \pm 0.001$ \\
\hline M11 & $2.925 \pm 0.021$ & $0.275 \pm 0.017$ & $0.577 \pm 0.001$ & ND & ND & ND & $3.349 \pm 0.026$ \\
\hline M12 & $2.363 \pm 0.003$ & $0.462 \pm 0.043$ & $0.643 \pm 0.007$ & ND & ND & ND & $2.332 \pm 0.001$ \\
\hline M13 & $2.200 \pm 0.005$ & $0.214 \pm 0.061$ & $0.560 \pm 0.005$ & ND & ND & ND & $2.990 \pm 0.002$ \\
\hline M14 & $1.529 \pm 0.007$ & $0.313 \pm 0.011$ & $0.669 \pm 0.018$ & ND & ND & ND & $7.021 \pm 0.011$ \\
\hline M15 & $1.886 \pm 0.002$ & $0.284 \pm 0.004$ & $0.555 \pm 0.012$ & ND & ND & ND & $5.074 \pm 0.043$ \\
\hline MD 1 & ND & $5.449 \pm 0.011$ & $3.157 \pm 0.032$ & $0.597 \pm 0.004$ & $1.963 \pm 0.044$ & $1.629 \pm 0.009$ & $4.473 \pm 0.016$ \\
\hline MD 2 & ND & $5.480 \pm 0.032$ & $3.402 \pm 0.022$ & $0.653 \pm 0.008$ & $1.825 \pm 0.002$ & $1.436 \pm 0.021$ & $4.718 \pm 0.001$ \\
\hline MD 3 & ND & $4.372 \pm 0.049$ & $2.785 \pm 0.021$ & $0.616 \pm 0.001$ & $1.793 \pm 0.005$ & $2.128 \pm 0.032$ & $4.149 \pm 0.001$ \\
\hline MD 4 & ND & $3.171 \pm 0.002$ & $3.648 \pm 0.001$ & $0.628 \pm 0.006$ & $1.721 \pm 0.001$ & $2.287 \pm 0.028$ & $4.835 \pm 0.006$ \\
\hline MD 5 & $0.047 \pm 0.001$ & $4.239 \pm 0.049$ & $3.675 \pm 0.071$ & $0.504 \pm 0.012$ & $1.695 \pm 0.011$ & $1.921 \pm 0.025$ & $3.575 \pm 0.019$ \\
\hline MD 6 & ND & $5.579 \pm 0.024$ & $3.717 \pm 0.001$ & $0.661 \pm 0.008$ & $1.639 \pm 0.025$ & $2.061 \pm 0.066$ & $4.915 \pm 0.022$ \\
\hline MD 7 & ND & $3.603 \pm 0.052$ & $3.429 \pm 0.003$ & $0.531 \pm 0.005$ & $1.969 \pm 0.039$ & $1.655 \pm 0.004$ & $4.568 \pm 0.001$ \\
\hline MD 8 & ND & $2.456 \pm 0.011$ & $3.406 \pm 0.004$ & $0.637 \pm 0.001$ & $1.731 \pm 0.041$ & $1.373 \pm 0.011$ & $5.590 \pm 0.021$ \\
\hline MD 9 & ND & $6.547 \pm 0.002$ & $2.995 \pm 0.012$ & $0.709 \pm 0.011$ & $1.687 \pm 0.032$ & $1.672 \pm 0.031$ & $7.210 \pm 0.004$ \\
\hline MD 10 & ND & $5.517 \pm 0.038$ & $3.151 \pm 0.019$ & $0.651 \pm 0.024$ & $1.7540 \pm 0.004$ & $2.005 \pm 0.002$ & $5.935 \pm 0.006$ \\
\hline
\end{tabular}

Quercetin was present in MD2 and Josaphine samples except in Morris samples. This may be due to MD2 as a hybrid or genetically modified seedlings derived from Josaphine by the Malaysian Agriculture Research and Development Institute (MARDI) [20]. Even though the similarities and differences among the three varieties of pineapple can be observed in the chromatographic fingerprints obtained, a more systematic approach in varietal discrimination was further evaluated using chemometric techniques as this approach will help to discriminate even the slightest variation of bioactive compounds [21]. 


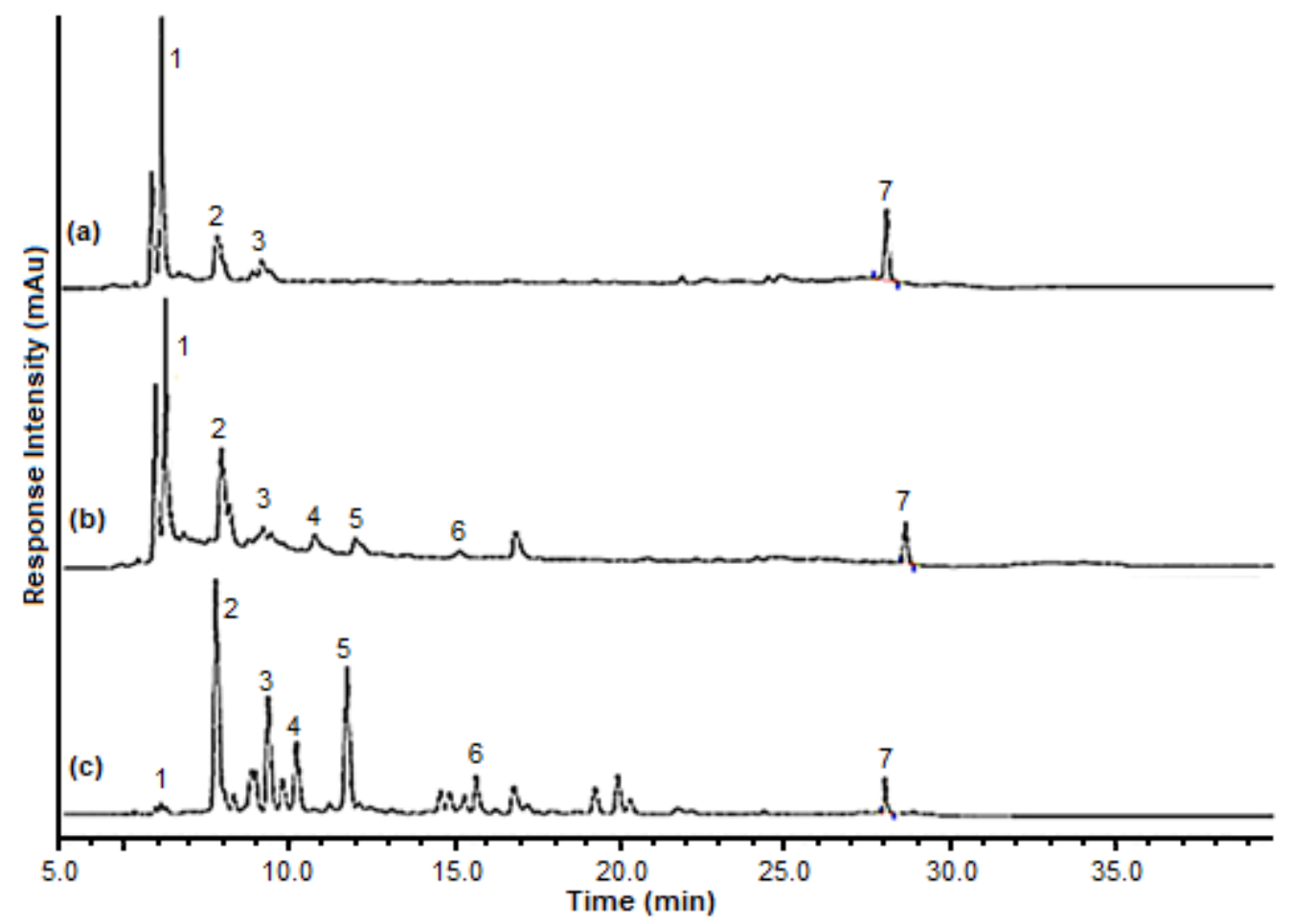

Fig 2. Representative chromatographic fingerprints of three different varieties of pineapples obtained at $280 \mathrm{~nm}$ (a) Morris (b) Josaphine (c) MD2. 1) catechin; 2) epicatechin; 3) chlorogenic acid; 4) ferulic acid; 5) myricetin; 6) quercetin; 7) bromelain

\section{Chemometric Analysis}

For chemometric analysis, relative peak areas of 16 peaks were selected inclusive of 7 identified bioactive compounds and 9 unknown compounds. A larger number of variables were needed to perform thorough varietal discrimination.

\section{Cluster Analysis (CA)}

Cluster analysis is a multivariate method that aims to classify a sample of subjects (or objects) on the basis of a set of measured variables into a number of different groups such that similar subjects are placed in the same group [22]. The dataset was grouped using Ward's linkage with squared Euclidean distance as a measure of similarity [23]. Fig. 3 shows the dendrogram obtained. The three pineapple varieties were clearly grouped in individual clusters. However, within each cluster, subgroups could be observed due to the origin (location) and maturity of samples. Maturity can affect significantly the different composition of bioactive compounds in fruits [24].

\section{Principle Component Analysis (PCA)}

PCA has been implemented in many recent studies for authentication and classification in food [25-28]. It was also used in a recent study to determine the seasonal and regional variation in food authentication based on chromatographic fingerprinting [29]. The variation in the chromatographic fingerprints of each pineapple varieties analyzed by PCA (Fig. 4) yielded 3 principal components (PCs) also known as varimax factors analyzed with some of them consist of strong factor loading as shown in Table 3.

Data variance was explained in the first two PCs with a cumulative variability of $75.28 \%$. Chlorogenic acid and ferulic acid possessed a strong loading in PC1. Other significant variables in PC1 could not be identified. In PC2, epicatechin and bromelain gave strong loadings. Fig. 5 shows the PCA score plot of the pineapple samples. The groupings in the score plot were in good agreement with the result obtained from CA whereby the three varieties existed in different axes. Our 


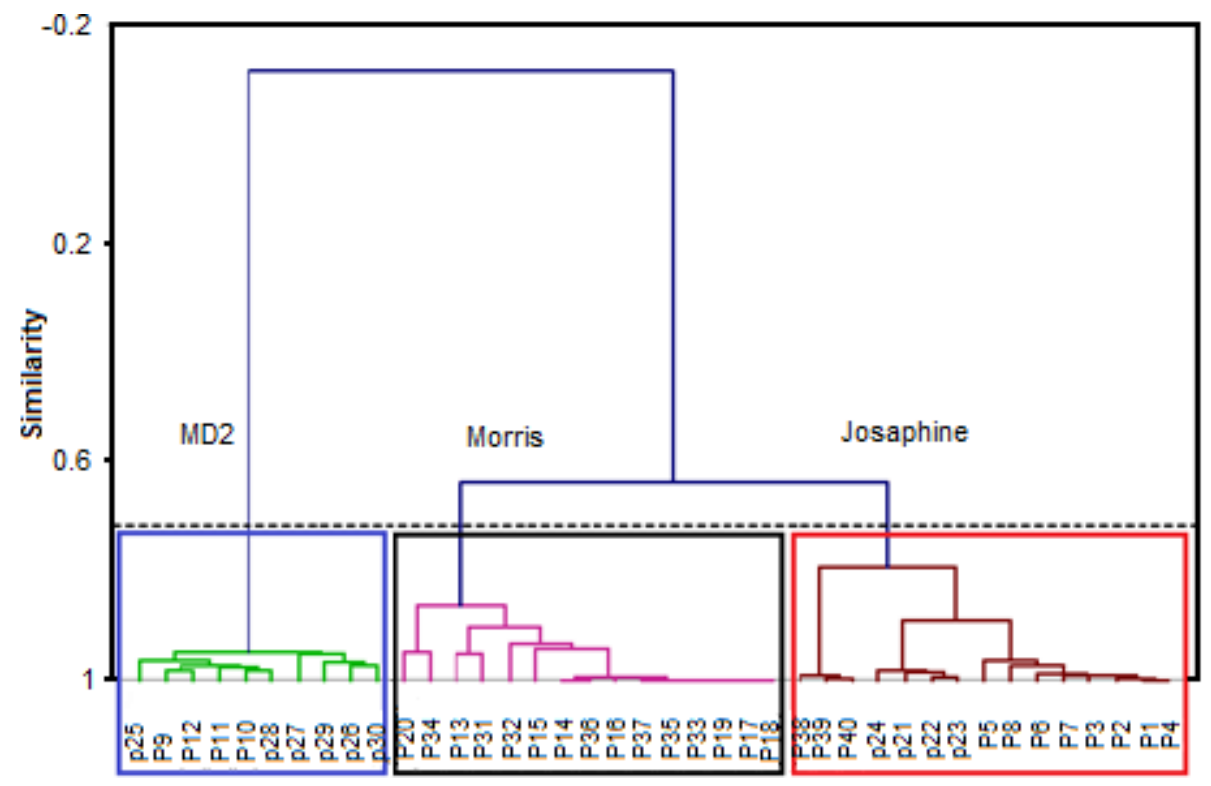

Fig 3. Dendrogram of three varieties of pineapple

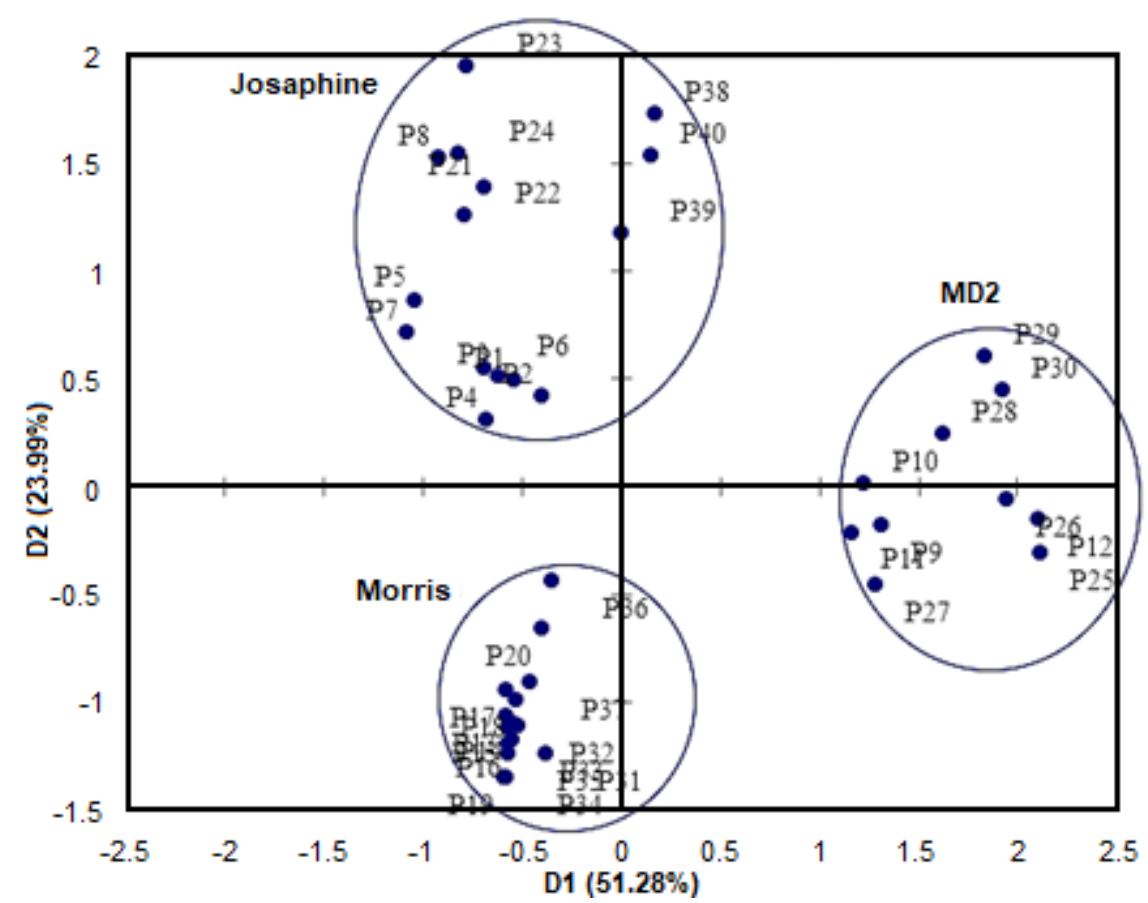

Fig 4. PCA score plot of pineapple samples. Observation was done after varimax rotation

previous studies had successfully applied CA and PCA on the authentication of Harumanis mango [30] and the clustering of Tongkat Ali roots [17].

With the aids of chemometric techniques such as PCA and CA, significant parameters, chlorogenic acid and ferulic acid concentration in each pineapple variety were further analyzed. Fig. 5 shows a graph of the ratio of the two major bioactive compounds. The ratio of these two compounds in the three varieties of pineapple differed from each other. In Josaphine variety, the ratio of chlorogenic acid and ferulic acid concentration in the samples has only small differences where the concentration of chlorogenic acid is higher than ferulic acid. However, in MD2 variety, large differences can be 
Table 3. Factor loadings for bioactive compounds detected in pineapple samples. (Strong loadings $>0.75$ are shown in bold)

\begin{tabular}{lccc}
\hline Parameters & PC1 & PC2 & PC3 \\
\hline X1 & 0.165 & 0.294 & 0.038 \\
Catechin & 0.655 & 0.196 & 0.009 \\
Epicatechin & 0.020 & $\mathbf{0 . 8 0 5}$ & 0.077 \\
X4 & 0.102 & 0.737 & 0.074 \\
Chlorogenic acid & $\mathbf{0 . 8 1 6}$ & 0.074 & 0.053 \\
X6 & 0.088 & 0.542 & 0.030 \\
Ferulic acid & $\mathbf{0 . 8 9 9}$ & 0.004 & 0.043 \\
X8 & $\mathbf{0 . 8 5 4}$ & 0.009 & 0.095 \\
X9 & $\mathbf{0 . 8 2 4}$ & 0.037 & 0.062 \\
X10 & 0.337 & 0.109 & 0.470 \\
X11 & $\mathbf{0 . 9 1 0}$ & 0.000 & 0.037 \\
Quercetin & 0.209 & 0.136 & 0.603 \\
X13 & $\mathbf{0 . 8 4 5}$ & 0.023 & 0.028 \\
Myricetin & 0.564 & 0.044 & 0.342 \\
X15 & $\mathbf{0 . 8 9 0}$ & 0.000 & 0.024 \\
Bromelain & 0.027 & $\mathbf{0 . 8 3 1}$ & 0.000 \\
\hline Eigenvalue & 9.838 & 4.132 & 0.693 \\
Variability (\%) & 51.28 & 23.99 & 12.41 \\
Cumulative (\%) & 51.28 & 75.28 & 87.69 \\
\hline
\end{tabular}

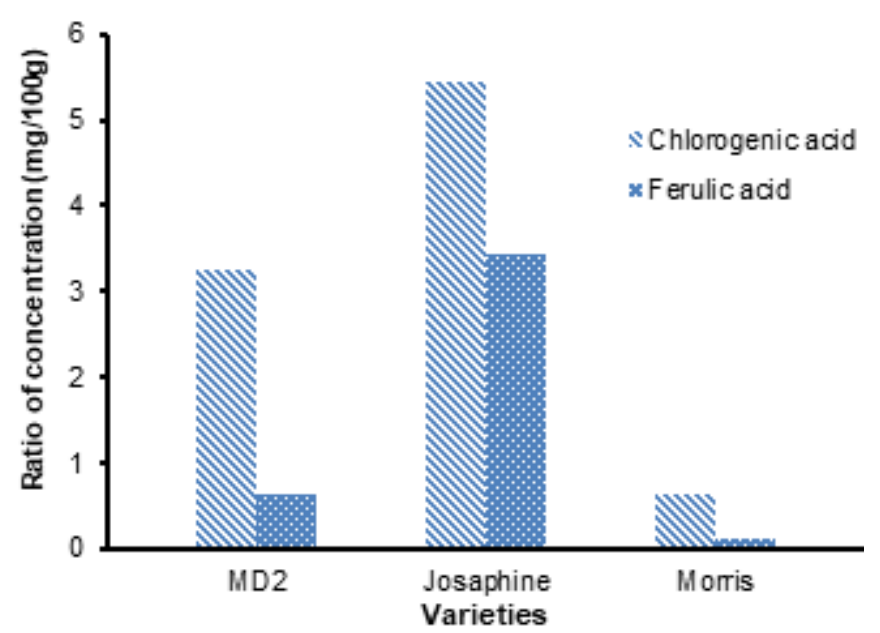

Fig 5. Ratio of concentration (mg/100 g) of chlorogenic acid and ferulic acid for three varieties of pineapples

observed in the ratio of the two compounds whereby, the concentration of chlorogenic acid is almost six times higher than that of ferulic acid. Similar to MD2 variety, chlorogenic acid in Morris variety is higher than ferulic acid. However, the total amount of these two compounds was very much lower than those in Josaphine variety. Due to the differences in the ratio of these two compounds, the amount of chlorogenic acid and ferulic acid could be promising marker compounds to distinguish these three varieties.

\section{- CONCLUSION}

A comprehensive and reliable chromatographic fingerprint of pineapple was obtained using PLE followed by the online SPE-LC method. The complex data of 16 compounds from 40 samples were interpreted using multivariate data analyses (CA and PCA) which successfully discriminated the three pineapple varieties. This study suggested that chromatographic fingerprints with chemometric evaluation can provide a systematic approach in quality control and authentication of fruit varieties.

\section{- ACKNOWLEDGMENTS}

The authors would like to acknowledge the financial support obtained from Ministry of Education Malaysia for this project (Project number: FRGS 1/2018/ STG01/UiTM/02/8) and Universiti Teknologi MARA.

\section{- REFERENCES}

[1] Yapo, E.S., Kouakou, H.T., Kouakou, L.K., Kouadio, J.Y., Kouamé, P., and Mérillon, J., 2011, Phenolic profiles of pineapple fruits (Ananas comosus L. Merrill) influence of the origin of suckers, Aust. J. Basic Appl. Sci., 5 (6), 1372-1378.

[2] Wen, L., 2001, Pineapple juice: Phenolic composition and enzymatic browning inhibition, Dissertation, Oregon State University, United States.

[3] Larrauri, J.A., Rupérez, P., and Saura-Calixto, F., 1997, Pineapple shell as a source of dietary fiber with associated polyphenols, J. Agric. Food Chem., 45 (10), 4028-4031.

[4] Chaisakdanugull, C., Theerakulkait, C., and Wrolstad, R.E., 2007, Pineapple juice and its fractions in enzymatic browning inhibition of banana, J. Agric. Food Chem., 55 (10), 4252-4257.

[5] Hale, L.P., Greer, P.K., Trinh, C.T., and Gottfried, M.R., 2005, Treatment with oral bromelain decreases colonic inflammation in the IL-10- 
deficient murine model of inflammatory bowel disease, Clin. Immunol., 116 (2), 135-142.

[6] Reid, L.M., O’Donnell, C.P., and Downey, G., 2006, Recent technological advances for the determination of food authenticity, Trends Food Sci. Technol., 17 (7), 344-353.

[7] Saad, A.M.A., 2016, An investigation into the implementation of total quality environmental management (TQEM) for sustainability in Lybian food industry, Dissertation, Nottingham Trent University, United Kingdom.

[8] Gong, F., Liang, Y.Z., Xie, P.S., and Chau, F.T., 2003, Information theory applied to chromatographic fingerprint of herbal medicine for quality control, $J$. Chromatogr. A, 1002 (1-2), 25-40.

[9] Chun, M.H., Kim, E.K., Yu, S.M., Oh, M.S., Moon, K.Y., Jung, J.J., and Hong, J., 2011, GC/MS combined with chemometrics methods for quality control of Schizonepeta tenuifolia Briq: Determination of essential oils, Microchem. J., 97 (2), 274-281.

[10] Stanek, N., and Jasicka-Misiak, I., 2018, HPTLC phenolic profiles as useful tools for the authentication of honey, Food Anal. Methods, 11, 2979-2989.

[11] Bajoub, A., Bendini, A., Fernández-Gutiérrez, A., and Carrasco-Pancorbo, A., 2018, Olive oil authentication: A comparative analysis of regulatory frameworks with especial emphasis on quality and authenticity indices, and recent analytical techniques developed for their assessment. A review, Crit. Rev. Food Sci. Nutr., 58 (5), 832-857.

[12] Bengana, M., Bakhouche, A., Lozano-Sánchez, J., Amir, Y., Youyou, A., Segura-Carretero, A., and Fernández-Gutiérrez, A., 2013, Influence of olive ripeness on chemical properties and phenolic composition of Chemlal extra-virgin olive oil, Food Res. Int., 54 (2), 1868-1875.

[13] Fan, X.H., Cheng, Y.Y., Ye, Z.L., Lin, R.C. and Qian, Z.Z., 2006, Multiple chromatographic fingerprinting and its application to the quality control of herbal medicines, Anal. Chim. Acta, 555 (2), 217-224.

[14] Petersson, E.V., Liu, J., Sjöberg, P.J.R., Danielsson, R., and Turner C., 2010, Pressurized hot water extraction of anthocyanins from red onion: A study on extraction and degradation rates, Anal. Chim. Acta, 663 (1), 27-32.

[15] Hartonen, K., Parshintsev, J., Sandberg, K., Bergelin, E., Nisula, L., and Riekkola, M.L., 2007, Isolation of flavonoids from aspen knotwood by pressurized hot water extraction and comparison with other extraction techniques, Talanta, 74 (1), 32-38.

[16] Khan, A.A.M., Saim, N., and Hamid, R.D., 2017, Optimisation of pressurised liquid extraction of bioactive compounds from Ananas comosus (pineapple) fruit, Pertanika J. Sci. Technol., 25 (S), 175-182.

[17] Zaini, N.N., Osman, R., Juahir, H., and Saim, N., 2016, Development of chromatographic fingerprints of Eurycoma longifolia (Tongkat Ali) roots using online solid phase extraction-liquid chromatography (SPE-LC), Molecules, 21 (5), E583.

[18] Li, T., Shen, P., Liu, W., Liu, C., Liang, R., Yan, N., and Chen, J., 2014, Major polyphenolics in pineapple peels and their antioxidant interactions, Int. J. Food Prop., 17 (8), 1805-1817.

[19] Fine, A.M., 2000, Oligomeric proanthocyanidin complexes: History, structure, and phytopharmaceutical applications, Altern. Med. Rev., 5 (2), 144-151.

[20] Mazalan, M.F., and Yusof, Y., 2017, Natural pineapple leaf fibre extraction on Josapine and Morris, MATEC Web Conf., 135, 00043.

[21] Bevilacqua, M., Bro, R., Marini, F., Rinnan, Å., Rasmussen, M.A., and Skov, T., 2017, Recent chemometrics advances for foodomics, $\operatorname{Tr} A C$, Trends Anal. Chem., 96, 42-51

[22] Gad, H.A., El-Ahmady, S.H., Abou-Shoer, M.I., and Al-Azizi, M.M., 2013, Application of chemometrics in authentication of herbal medicines: A review, Phytochem. Anal., 24 (1), 1-24.

[23] Perestrelo, R., Barros, A.S., Rocha, S.M., and Câmara, J.S., 2014, Establishment of the varietal profile of Vitis vinifera L. grape varieties from different geographical regions based on HSSPME/GC-qMS combined with chemometric tools, Microchem. J., 116, 107-117.

[24] Soifoini, T., Donno, D., Jeannoda, V., Rakotoniaina, 
E., Hamidou, S., Achmet, S.M., Solo, N.R., Afraitane, K., Giacoma, C., and Beccaro, G.L., 2018, Bioactive compounds, nutritional traits, and antioxidant properties of Artocarpus altilis (Parkinson) fruits: Exploiting a potential functional food for food security on the Comoros Islands, J. Food Qual., 2018, 5697928.

[25] Belmonte-Sánchez, J.R., Gherghel, S., ArrebolaLiébanas, J., González, R.R., Vidal, J.L.M., Parkin, I., and Frenich, A.G., 2018, Rum classification using fingerprinting analysis of volatile fraction by headspace solid phase microextraction coupled to gas chromatography-mass spectrometry, Talanta, 187, 348-356.

[26] Efenberger-Szmechtyk, M., Nowak, A., and Kregiel, D., 2018, Implementation of chemometrics in quality evaluation of food and beverages, Crit. Rev. Food Sci. Nutr., 58 (10), 1747-1766.

[27] Neto, S., 2018, Classification and authentication of plants by chemometric analysis of spectral data, Compr. Anal. Chem., 80, 105-125.

[28] Rafi, M., Jannah, R., Heryanto, R., Kautsar, A., and Septaningsih, D., 2018, UV-Vis spectroscopy and chemometrics as a tool for identification and discrimination of four Curcuma species, Int. Food Res. J., 25 (2), 643-648.

[29] Wang, Y., and Jin, Y., 2017, Development and distinction of Rhizoma rodgersiae with HPLC-DAD fingerprint analysis combined with chemical pattern recognition techniques, Am. J. Anal. Chem., 8, 681-689.

[30] Zakaria, S.R., Saim, N., Osman, R., Abdul Haiyee, Z., and Juahir, H., 2018, Combination of sensory, chromatographic, and chemometrics analysis of volatile organic compounds for the discrimination of authentic and unauthentic Harumanis mangoes, Molecules, 23 (9), E2365. 